\title{
Assessment of Level of Dependence and Awareness among Tobacco Users in Jodhpur, Rajasthan
}

\author{
Dr. Nitin Kumar Joshi ${ }^{1}$, Dr. Vibha Joshi ${ }^{2}$ \\ I'Jodhpur School of Public Health, Jodhpur National University, Rajasthan) \\ ${ }^{2}$ (Department of Public Health, Lachoo Memorial College, Jodhpur, Rajasthan)
}

\begin{abstract}
Tobacco use and the subsequent health problems are of major concern today. Tobacco consumption has been identified as the single most preventable cause of death and disease in India. Different studies have proved that tobacco dependency and lack of awareness about harmful effects of tobacco are the major obstacle in the process of quitting the habit. The present study is an attempt to explore the tobacco dependence status and level of awareness among tobacco users in Jodhpur city. A cross sectional study was conducted amongst the general population who participated in various health checkup camps held in different localities of Jodhpur city. The study comprised of 500 subjects. Willingness to quit and awareness level of tobacco use revealed poor response among the subjects. There is an urgent need to take effective steps, especially in launching community awareness and providing clinical and psychological support to overcome tobacco dependence.
\end{abstract}

Keywords: Public health, dependence, awareness, hazards, quit, tobacco.

\section{Introduction}

Tobacco use is the world's leading cause of death, accounting for 4 million deaths per year. On the basis of current use patterns by the year 2030, it may kill more than 10 million people annually ${ }^{[1]}$. Tobacco is addictive in all forms and it increases the risk of many cancers, oral diseases, heart attack, stroke, peripheral vascular disease, osteoporosis, chronic obstructive pulmonary disease, diabetes and adverse reproductive outcomes ${ }^{[1]}$. Even second-hand smoking adversely affects pregnancy outcomes and causes lung cancer and heart disease. By the year 2020, it is expected that tobacco-related illness will become the world's largest single health problem, causing an estimated 8.4 million deaths annually, claiming more lives than HIV, tuberculosis, maternal mortality, motor vehicle accidents, suicide, and homicide, combined. As tobacco use is increasing rapidly in many developing countries, while declining in many developed countries, the burden of disease caused by tobacco will shift dramatically. Deaths in developed regions are expected to rise nearly $50 \%$, from 1.6 million to 2.4 million, while deaths in Asia will soar almost four-fold from 1.1 million in 1990 to an estimated 4.2 million in the year $2020^{[2]}$. Tobacco use and the subsequent health problems are of major concern today. Tobacco consumption has been identified as the single most preventable cause of death and disease in India ${ }^{[3]}$.Different studies have proven that tobacco dependency and lack of awareness about harmful effect of tobacco is the major obstacle in the process of quitting the habit ${ }^{[4]}$. This study was done to assess the level of tobacco dependence and level of awareness about health hazards of tobacco use in tobacco (chewing and smoking) users.

\section{Methods}

The present study is a descriptive cross sectional survey, conducted to assess the awareness and tobacco dependence among general population. Data was collected from various health checkup camps conducted at different areas of Jodhpur city. Informed consent was obtained from the study subjects before the questionnaire was distributed. The investigator orally administered the consent forms for the illiterate participants. A pilot study of randomly selected 20 individuals was carried out to determine the feasibility and validity of the questionnaire and the amount of time required to complete the survey.

Questionnaire interviews were conducted to obtain information from 500 subjects who reported in various health check up camps. The self-administered questionnaire (with support provided to illiterate participants) of 26 questions was divided into five clusters for the ease of data collection. Majority of the questions were close-ended and few were open ended. Clusters were prepared to obtain information regarding demographics, socio economic status, tobacco addiction and awareness related to tobacco issues.

Participants 15 years above i.e. young, middle aged and the elderly were included in this study and those who did not give their consent were excluded. This survey was limited only to the subjects who reported in health check up camps. Codebook was prepared and data analysis was done. 


\section{Results}

Among the total population $(n=500)$ surveyed, $59.6 \%$ were males and $40.4 \%$ were females.

3.1 Tobacco dependence: The overall prevalence of Tobacco users (chewing and smoking) in the age group 15 year and above was $43.6 \%$ in males and $37.6 \%$ in females. Out of all tobacco users: $57.4 \%$ male and $53.8 \%$ females consumed tobacco daily, $18 \%$ females and $13.5 \%$ males consumed tobacco once daily, $38 \%$ males and $36 \%$ females consumed tobacco more than 3 times / day, $42 \%$ males and $36 \%$ females had strong cravings for tobacco, $44 \%$ males and $26 \%$ females had tobacco within 30 min after they woke up in morning, $31 \%$ males and $23 \%$ females were not willing to quit the habit of tobacco use. $33.3 \%$ males and $41 \%$ females had never tried to quit tobacco, $42 \%$ males and $51 \%$ females were not able to quit tobacco deliberately for more than a week.

3.2 Awareness: Out of all tobacco users: $21 \%$ males and $15.4 \%$ females were not aware about the harmful effect of tobacco, $28.4 \%$ males and $28 \%$ females were not aware about the oral health hazards caused by tobacco usage, $43.3 \%$ males and $48.7 \%$ females knew that cancer is the only health hazard caused by tobacco usage, Only .7\% males and $2.6 \%$ females were aware about tobacco related health hazards other than cancer, $72 \%$ males and $68 \%$ females had never participated in tobacco cessation program. $34 \%$ males and $41 \%$ females, who visited health services clinics in the past 12 months, were not informed about the dangers of tobacco use.

Table No. 1: Tobacco Usage

\begin{tabular}{lllll}
\hline Gender & $\begin{array}{l}\text { Tobacco } \\
\text { Users\% }\end{array}$ & $\begin{array}{l}\text { Chewing Tobacco } \\
\text { Users\% } \\
\text { (Tobacco, Gutka and } \\
\text { other) }\end{array}$ & $\begin{array}{l}\text { Smoking Tobacco } \\
\text { User\% } \\
\text { (Cigarette, Bidi and } \\
\text { other) }\end{array}$ & $\begin{array}{l}\text { Tobacco chewing and } \\
\text { smoking, User\% } \\
\text { (Both-Chewing and } \\
\text { Smoking)) }\end{array}$ \\
\hline Male(n=298) & 43.6 & 25.1 & 15.8 & 2.2 \\
Female $(\mathrm{n}=202)$ & 37.6 & 30.6 & 5.8 & 1.2 \\
\hline
\end{tabular}

Table No. 2: Tobacco dependency

\begin{tabular}{llll}
\hline Gender & $\begin{array}{l}\text { Daily Tobacco } \\
\text { Consumers } \\
\text { Users\%(out of all tobacco users) }\end{array}$ & $\begin{array}{l}\text { Consume Tobacco more than 3 times / } \\
\text { day } \\
\text { Users\%(out of all tobacco users) }\end{array}$ & $\begin{array}{l}\text { Strong cravings for Tobacco } \\
\text { Users\%(out of all tobacco users) }\end{array}$ \\
\hline Male & 57.4 & 28.4 & 42 \\
Female & 53.8 & 28 & 36 \\
\hline
\end{tabular}

Table No. 3: Awareness and willingness to quit

\begin{tabular}{llll}
\hline Gender & $\begin{array}{l}\text { Not aware about harmful effect of } \\
\text { tobacco Users\%(out of all tobacco } \\
\text { users) }\end{array}$ & $\begin{array}{l}\text { Not aware of oral health hazards } \\
\text { caused by tobacco usage, Users\%(out } \\
\text { of all tobacco users) }\end{array}$ & $\begin{array}{l}\text { Not willing to quit habit of } \\
\text { tobacco use Users\%(out of all } \\
\text { tobacco users) }\end{array}$ \\
\hline Male & 21 & 38 & 31 \\
Female & 15.4 & 36 & 23 \\
\hline
\end{tabular}

\section{Conclusions}

Effective treatment for tobacco users should be given more attention, as tobacco dependence is a chronic condition that often requires repeated intervention and multiple attempts to quit. Treatment of tobacco dependence should be an integral part of any comprehensive tobacco control programme as indicated in the WHO FCTC ${ }^{[5]}$. Significant proportion of tobacco users have never participated in tobacco cessation programs and were not informed of the health hazards of tobacco during their visit to health care facilities. This shows that despite various tobacco cessation activities and programs, the health risks of tobacco use are not significantly controlled and there is a lack of enthusiasm for tobacco cessation advocacy among health care providers. There is a need to emphasize the role of every health professional as a clinician, educator, administrator and public health advocate in tobacco control. ${ }^{[6-8]}$. Awareness level towards tobacco chewing revealed poor response among the subjects and dependency on tobacco was high. There is an urgent a need to take effective steps, especially on launching community awareness programs for school-age children and public to educate them about the consequences of tobacco use, and on counseling of patients for de-addiction of this habit ${ }^{[9]}$. Improved health education for anti tobacco use and awareness generation of tobacco-related health hazards should be strongly recommended as a preventive measure ${ }^{[10]}$. This study emphasizes a pressing need for more comprehensive messaging of the harmful repercussions of tobacco use. 


\section{Reference}

[1] Prakash C. Gupta: The Public Health Impact of Tobacco, Special Section: Cancer, Current Science, Vol. 81, No. 5, 10 September 2001

[2] Murray, C. J. L. and Lopez, A. D., Lancet, 1997, 349, 1498-1504

[3] Prakash C. Gupta and Samira Asma: Bidi Smoking and Public Health ,Ministry of Health and Family Welfare, March 208

[4] A S M Abdullah, C G Husten : Promotion of smoking cessation in developing countries: a framework for urgent public health interventions, Thorax 2004;59:623630 doi:10.1136/thx.2003.018820

[5] World Health Organization: WHO Framework Convention on Tobacco Control. Geneva: World Health Organization; 2003

[6] US Department of Health and Human Services. Reducing tobacco use: a report of the Surgeon General. Atlanta, GA: US Department of Health and Human Services, CDC; 2000

[7] Fiore MC, Bailey WC, Cohen SJ, et al. Treating tobacco use and dependence. Clinical practice guideline. Rockville, MD: US Department of Health and Human Services; 2000.

[8] Lancaster T, Stead L, Silagy C, et al. Effectiveness of interventions to help people stop smoking: findings from the Cochrane Library. BMJ 2000; 321:355--8.

[9] Dr. Sushil B. Naik, Dr. Swapnil N, et el. Awareness about Tobacco Habit, Its Hazards and Willingness to quit the Habit among Patients. IOSR Journal of Dental and Medical Sciences. ISSN: 2279-0853, ISBN: 2279-0861,2013

[10] Roychowdhury S, Roychowdhury G, Sen U. Assessment of awareness level on tobacco and smoking habits as risk factors for cancer among lung and laryngeal cancer patients in Kolkata. Asian Pac J Cancer Prev. 2005 Jul-Sep;6(3):332-6. 